\title{
Preterm pre-labor rupture of membranes and perinatal outcome: a prospective cohort study
}

\author{
Kumar N ${ }^{1}$, Yadav A. ${ }^{2}$ \\ ${ }^{1}$ Dr. Naina Kumar, Associate Professor, Department of Obstetrics and Gynecology, All India Institute of Medical \\ Sciences, Mangalagiri, Guntur, Andhra Pradesh, India, ${ }^{2}$ Dr. Ashu Yadav, Postgraduate student $3^{\text {rd }}$ year, Department of \\ Obstetrics and Gynecology, Maharishi Markandeshwar Institute of Medical Sciences and Research, Mullana, Ambala, \\ Haryana, India.
}

Corresponding Author: Dr. Naina Kumar, Associate Professor, Department of Obstetrics and Gynecology, All India Institute of Medical Sciences, Mangalagiri, Guntur, Andhra Pradesh, India. E-mail: drnainakumar@gmail.com

\begin{abstract}
Background: Preterm Prelabor Rupture of Membranes (PPROM) is one of the common causes of increased perinatal morbidity and mortality. Objectives: To know the perinatal outcome in antenatal women with Preterm Prelabor Rupture of Membranes. Methods: Present prospective cohort study was conducted in rural tertiary center of Northern India over one year (January-December 2018) on 75 antenatal women at gestation $\geq 28$ weeks with Preterm Prelabor Rupture of Membranes. Onset of labor and mode of delivery was recorded in all participants. Immediately after birth, neonatal Apgar scores, birth weight, gender, NICU admission, need for oxygen or intubation, complications and perinatal mortality (early neonatal deaths and stillbirths) were recorded. Results: Of total 3,085 deliveries (at gestation $\geq 28$ weeks) during the study period, $75(2.4 \%)$ antenatal women had PPROM, of which $72(96.0 \%)$ had preterm delivery and three $(4.0 \%)$ were managed conservatively and delivered atterm. Four $(5.6 \%)$ had iatrogenic preterm delivery (labor was induced) due to feto-maternal risk factors and 68(94.4\%) went into spontaneous preterm labor. The most common mode of delivery was vaginal $(81.3 \%)$ followed by Lower segment cesarean section (18.7\%). Of 75 neonates delivered, 70 $(93.3 \%)$ were live, 03(4.0\%) stillbirths and 02(2.7\%) early neonatal deaths. The mean neonatal birth weight was $2.02 \pm 0.50 \mathrm{Kg}(\mathrm{p}=0.000)$. Sixty-seven $(89.3 \%)$ neonates had poor 1-minute Apgar scores, 17(22.7\%) had 5-minutes Apgar score <7, 40 (53.3\%) required NICU admission, 06(8.0\%) intubated, 45(60.0\%) developed neonatal complications. The most common neonatal complication was prematurity $(58.7 \%)$ followed by Respiratory distress syndrome (44.0\%). Conclusion: Preterm Prelabor Rupture of Membranes was significantly associated with adverse perinatal outcome.
\end{abstract}

Keywords: Antenatal; Birth weight; Gestation; Labor; Preterm Prelabor rupture of membranes.

\section{Introduction}

Preterm Prelabor Rupture of Membranes (PPROM) is one of the leading causes of perinatal morbidity and mortality all over the world [1]. PPROM is defined as rupture of membranes before 37 completed weeks of gestation. It complicates an estimated $2-4 \%$ of all singleton pregnancies and $7-20 \%$ of multifetal gestations and is responsible for around $18-20 \%$ of all perinatal deaths [2,3]. The exact cause of PPROM is still not known, but various factors are known to play role in its pathogenesis, of which Choriodecidual infection or inflammation is an important factor,

Manuscript received: $28^{\text {th }}$ July 2019

Reviewed: $7^{\text {th }}$ August 2019

Author Corrected: $14^{\text {th }}$ August 2019

Accepted for Publication: $19^{\text {th }}$ August 2019 especially at early gestation [4]. Other causative factors include history of PPROM in previous pregnancy, multifetal gestation, low socio-economic status, polyhydramnion, smoking, vaginal infections or bleeding, amniocentesis, etc [5]. PPROM occurs due to stretching of fetal membranes ad microbial infection resulting in release of local inflammatory factors like cytokines and interleukins which in turn leads to collagenolysis mediated mechanical disruption, and weakening of membranes [5-8]. Furthermore, PPROM results in $25-40 \%$ cases of preterm births annually [9]. Hence, PPROM is one of the common causes of preterm birth and its complications, like respiratory distress syndrome, necrotizing enterocolitis, neonatal sepsis, bronchopulmonary hypoplasia or dysplasia, 
Original Research Article

intraventricular hemorrhage, periventricular leukomalacia, Cord Prolapse all leading to increased risk of perinatal morbidity and mortality $[10,11]$. In mothers it leads to increased risk of chorioamnionitis, cervical dystocia, dysfunctional labor, increase operative interference, postpartum hemorrhage, endometritis etc [12].

Hence, the present study was conducted with the aim to know the overall perinatal outcome in antenatal women at gestation $\geq 28$ weeks with PPROM in a rural tertiary care center of Northern India.

\section{Material and Methods}

Study design, setting and duration: The present prospective cohort study was conducted in the department of Obstetrics and Gynecology of a rural tertiary care center of Northern India over one year from January 2018 to December 2018 on 75 antenatal women at gestation $\geq 28$ weeks admitted with features of spontaneous Preterm Prelabor Rupture of Membranes.

Inclusion criteria: All antenatal women with singleton pregnancy at gestation $\geq 28$ weeks with spontaneous PPROM.

Exclusion criteria: Antenatal women with gestation $<28$ weeks, with multifetal gestation, women with chorioamnionitis, iatrogenic PPROM and those not willing to be a part of study were excluded.

Methodology- After obtaining approval from the Institutional Ethical Committee and informed written consent from all the participants in their own language, a total of 75 participants was enrolled in the study with spontaneous PPROM, confirmed by history and on per speculum examination (sudden gush or trickle of amniotic fluid seen coming through cervical external os).

A thorough history and physical examination including general, per-abdominal and vaginal examination (per speculum and prevaginal) of all the participants fulfilling the inclusion criteria was recorded. The various demographic features including age, gravidity, parity, gestational age, duration of PPROM, onset of labor, mode of delivery and perinatal outcome were recorded on a preformed data collection sheet.

Immediately after delivery by any route the 1 and 5minutes Apgar scores, neonatal gender and birth weight were recorded by the pediatrician on duty. Also, the need for resuscitation, NICU admission, intubation, complications and early neonatal deaths were assessed by a senior pediatrician and recorded.

The data thus collected included age, gravidity, parity, onset of labor, mode of delivery, perinatal mortality (including stillbirths and neonatal deaths) and morbidity (preterm birth, low birthweight, NICU admission, need for intubation, complications).

Statistical analysis- Statistical analysis of all the data was done using software SPSS version 22.0. Unpaired $t$ test was used for comparison between two continuous variables, Chi-Square test or Fisher's exact test was used to establish correlation of qualitative variables and ANOVA/Kruskal Wallis test was used for comparison between more than two groups. A p value of $<0.05$ was considered statistically significant.

\section{Results}

Of total 3,085 deliveries of antenatal women at gestation $\geq 28$ weeks during the study period, $75(2.4 \%)$ women had PPROM. The average (SD) age of these women was $25.78 \pm 3.81$ years with a minimum of 20 years and maximum of 38 years. The average gestational age at the time of delivery was $34.50 \pm 2.17$ weeks. Most of the women were multigravida (61.33\%). Of total 75 participants, $71(94.7 \%)$ women went into spontaneous labor and four (5.3\%) were induced for fetomaternal risk factors. There were $72(96.0 \%)$ preterm deliveries and three $(4.0 \%)$ term deliveries because of successful conservative management. The most common mode of delivery was vaginal $(81.3 \%)$ followed by Lower segment cesarean section (18.7\%). The various demographic features are depicted in Table 1.

The average birth weight of all 75 neonates was $2.02 \pm 0.50 \mathrm{Kg}$ with $14(18.7 \%)$ having $>2.5 \mathrm{~kg}, 46$ (61.3\%) low birth weight, $13(17.3 \%)$ very low birth weight and $02(2.7 \%)$ extremely low birth weight $(\mathrm{p}=0.000)$. The average 1 and 5 minutes Apgar scores of all the neonates was 4.36 \pm 3.34 and $8.09 \pm 1.91$ respectively.

PPROM was significantly associated with adverse perinatal outcome with 40 (53.3\%) neonates requiring NICU admission, $06(8.0 \%)$ ventilatory support, 45 (60.0\%) developed neonatal complications, $03(4.0 \%)$ stillbirths and 02 $(2.7 \%)$ early neonatal deaths as depicted in Table 2 . The most common neonatal complication was prematurity $(58.7 \%)$ followed by Respiratory distress syndrome (44.0\%) as shown in Figure 1. 
Table-1: Socio-demographic parameters.

\begin{tabular}{|c|c|c|c|}
\hline Parameters & $\mathbf{N}(\%)$ & Chi square test & p-value \\
\hline Age (years) & & \multirow{4}{*}{4.224} & \multirow{4}{*}{0.121} \\
\hline$<20$ & $02(2.7 \%)$ & & \\
\hline $21-30$ & $65(85.3 \%)$ & & \\
\hline$>30$ & $18(10.7 \%)$ & & \\
\hline \multicolumn{2}{|l|}{ Parity } & \multirow{3}{*}{2.453} & \multirow{3}{*}{0.874} \\
\hline Nulliparous & $35(46.7 \%)$ & & \\
\hline Multiparous & $40(53.3 \%)$ & & \\
\hline \multicolumn{2}{|l|}{ Gravidity } & \multirow{3}{*}{0.001} & \multirow{3}{*}{0.976} \\
\hline Primigravida & $29(38.7 \%)$ & & \\
\hline Multigravida & $46(61.3 \%)$ & & \\
\hline \multicolumn{2}{|c|}{ Gestation (weeks) at the time of delivery } & \multirow{4}{*}{325.817} & \multirow{4}{*}{0.000} \\
\hline Very preterm & $09(12.0 \%)$ & & \\
\hline Late preterm & $64(85.3 \%)$ & & \\
\hline Term & $02(2.7 \%)$ & & \\
\hline \multicolumn{2}{|l|}{ Onset of labor } & \multirow{3}{*}{12.943} & \multirow{3}{*}{0.002} \\
\hline Spontaneous & $71(94.7 \%)$ & & \\
\hline Induced & $04(5.3 \%)$ & & \\
\hline \multicolumn{2}{|l|}{ Mode of delivery } & \multirow{3}{*}{10.478} & \multirow{3}{*}{0.001} \\
\hline Vaginal & $61(81.3 \%)$ & & \\
\hline Lower segment cesarean section & $14(18.7 \%)$ & & \\
\hline \multicolumn{2}{|l|}{ Neonatal gender } & \multirow{3}{*}{0.004} & \multirow{3}{*}{0.949} \\
\hline Male & $40(53.3 \%)$ & & \\
\hline Female & 35 (46.7\%) & & \\
\hline \multicolumn{2}{|l|}{ Birth weight (Kg) } & \multirow{5}{*}{163.922} & \multirow{5}{*}{0.000} \\
\hline$\geq 2.5$ & $14(18.7 \%)$ & & \\
\hline$<2.5-\geq 1.5$ & $46(61.3 \%)$ & & \\
\hline$<1.5-\geq 1.0$ & $13(17.3 \%)$ & & \\
\hline$<1.0$ & $02(2.7 \%)$ & & \\
\hline \multicolumn{2}{|l|}{ Perinatal outcome } & \multirow{4}{*}{$\begin{array}{c}27.683 \\
28.238 \\
6.721\end{array}$} & \multirow{4}{*}{$\begin{array}{l}0.001 \\
0.000 \\
0.058\end{array}$} \\
\hline Live & $70(93.3 \%)$ & & \\
\hline Stillbirth & $03(4.0 \%)$ & & \\
\hline Neonatal death & $02(2.7 \%)$ & & \\
\hline
\end{tabular}


Original Research Article

Table-2: Preterm prelabor rupture of membranes and neonatal outcome

\begin{tabular}{|c|c|c|c|c|c|c|}
\hline Parameters & & $\mathbf{N}(\%)$ & Chi-square test & p-value & odds ratio & $95 \% \mathrm{CI}$ \\
\hline \multirow{2}{*}{ Preterm birth } & Yes & $72(96.0 \%)$ & \multirow{2}{*}{337.982} & \multirow{2}{*}{0.000} & \multirow{2}{*}{134.769} & \multirow{2}{*}{$42.28-429.57$} \\
\hline & No & $03(4.0 \%)$ & & & & \\
\hline \multirow{2}{*}{ 1-minute Apgar score } & $<7$ & $67(89.3 \%)$ & \multirow{2}{*}{4.403} & \multirow{2}{*}{0.036} & \multirow{2}{*}{2.164} & \multirow{2}{*}{$1.03-4.53$} \\
\hline & $>7$ & $08(10.7 \%)$ & & & & \\
\hline \multirow{2}{*}{ 5-minute Apgar score } & $<7$ & $17(22.7 \%)$ & \multirow{2}{*}{27.780} & \multirow{2}{*}{0.000} & \multirow{2}{*}{4.032} & \multirow{2}{*}{$2.31-7.05$} \\
\hline & $>7$ & $58(77.3 \%)$ & & & & \\
\hline \multirow{2}{*}{ Birth weight (Kg) } & $<2.5$ & $61(81.3 \%)$ & \multirow{2}{*}{103.746} & \multirow{2}{*}{0.000} & \multirow{2}{*}{11.521} & \multirow{2}{*}{$6.41-20.71$} \\
\hline & $\geq 2.5$ & $14(18.7 \%)$ & & & & \\
\hline \multirow{2}{*}{ NICU $^{*}$ admission } & Yes & $40(53.3 \%)$ & \multirow{2}{*}{93.897} & \multirow{2}{*}{0.000} & \multirow{2}{*}{7.412} & \multirow{2}{*}{$4.64-11.85$} \\
\hline & No & $35(46.7 \%)$ & & & & \\
\hline \multirow{2}{*}{ Ventilatory support } & Yes & $06(8.0 \%)$ & \multirow{2}{*}{6.473} & \multirow{2}{*}{0.011} & \multirow{2}{*}{2.911} & \multirow{2}{*}{$1.23-6.89$} \\
\hline & No & $69(92.0 \%)$ & & & & \\
\hline \multirow{2}{*}{$\begin{array}{l}\text { Neonatal } \\
\text { complication }\end{array}$} & Yes & $45(60.0 \%)$ & \multirow{2}{*}{75.913} & \multirow{2}{*}{0.000} & \multirow{2}{*}{6.38} & \multirow{2}{*}{$3.97-10.25$} \\
\hline & No & $30(40.0 \%)$ & & & & \\
\hline \multirow{2}{*}{ Stillbirth } & Yes & $03(4.0 \%)$ & & & & \\
\hline & No & $72(96.0 \%)$ & 28.238 & 0.000 & 15.41 & $4.01-59.31$ \\
\hline & Yes & $02(2.7 \%)$ & & & & \\
\hline Neonatal death & No & $73(97.3 \%)$ & 6.721 & 0.058 & 5.772 & $1.28-25.86$ \\
\hline
\end{tabular}

*NICU: Neonatal Intensive Care Unit

Table-3: Neonatal complications associated with preterm pre-labor rupture of membranes.

\begin{tabular}{|l|c|c|c|c|c|}
\hline Neonatal complications & N (\%) & $\begin{array}{c}\text { Chi-square } \\
\text { test }\end{array}$ & p-value & Odds Ratio & $\begin{array}{c}\text { 95\% Confidence } \\
\text { Interval }\end{array}$ \\
\hline Prematurity & $44(58.7 \%)$ & 298.445 & 0.000 & 22.05 & $13.60-35.76$ \\
\hline Respiratory distress & $33(44.0 \%)$ & 97.098 & 0.000 & 7.691 & $4.79-12.34$ \\
\hline Jaundice & $06(8.0 \%)$ & 0.162 & 0.687 & 1.19 & $0.51-2.77$ \\
\hline $\begin{array}{l}\text { Hypoxic ischemic } \\
\text { encephalopathy }\end{array}$ & $04(5.3 \%)$ & 1.978 & 0.160 & 2.063 & $0.74-5.78$ \\
\hline Sepsis & $03(4.0 \%)$ & 0.798 & 0.429 & 1.7 & $0.52-5.52$ \\
\hline Seizures & $02(2.7 \%)$ & 3.552 & 0.059 & 3.72 & $0.85-16.12$ \\
\hline
\end{tabular}

\section{Discussion}

Preterm Prelabor Rupture of Membranes is one of the most common cause for preterm deliveries and its associated complications leading to increased risk of perinatal morbidity and mortality worldwide. In the present study PPROM was found to be significantly associated with adverse perinatal outcomes. The average age of all the participants was $25.78 \pm 3.81$ years with majority belonging to 21-30 years age group $(85.3 \%)$, average gestation was $34.50 \pm 2.17$ weeks.
Most of the women were multigravida (61.33\%). PPROM was associated with $72(96.0 \%)$ cases of preterm delivery, poor Apgar scores at birth (89.3\% having $<7 \quad 1$-minute score), $40 \quad(53.3 \%) \quad$ NICU admissions, 06 (8.0\%) neonatal intubations, 45 (60.0\%) neonates having complication with prematurity $(58.7 \%)$ as most common complication followed by Respiratory distress syndrome (44.0\%) and Jaundice (8.0\%). Furthermore, PPROM was found to be associated with 
an overall perinatal mortality of $6.7 \%$ with $03(4.0 \%)$ still births and $02(2.7 \%)$ early neonatal deaths. Similar results were reported by a recent study which observed that PPROM was associated with a neonatal mortality of $7.4 \%$, major neonatal complications in $40 \%$, and increased rate of NICU admission in $72.9 \%$ neonates [1].

Similar to our results another study observed that PPROM was associated with adverse perinatal outcome with most common reason for perinatal mortality being prematurity and its complications. Also, the most common mode of delivery was vaginal (79\%) followed by cesarean section (21\%) [12]. A recent study observed that PPROM was more common in primigravida and most of the cases delivered vaginally (70.91\%). Furthermore, they found that PPROM was associated with higher maternal morbidity $(27.8 \%)$ and perinatal mortality (4.5\%) and morbidity (26.4\%) [13].

A recent study reported that PPROM was significantly associated with an increased risk of neonatal morbidity. They reported an overall neonatal survival to discharge rate of $33.8 \%$ and similar to the present study the most common neonatal morbidities were respiratory distress syndrome (78.7\%) and bronchopulmonary dysplasia (84.4\%) [14]. Similarly, a study observed a live birth rate of $63.6 \%$ and survival-to-discharge rate of $44.9 \%$ in women with PPROM at gestation $<24$ weeks, with respiratory distress syndrome, bronchopulmonary dysplasia and sepsis being the most common neonatal morbidities [15].

Another study observed similar results of $51.7 \%$ neonates as males and $48.3 \%$ female delivered to women with PPROM. $65 \%$ of women had vaginal delivery and $35 \%$ caesarean section. They also observed that Respiratory distress syndrome was the most common complication (36.7\%) followed by septicemia $(8.3 \%)$, meningitis (1.7\%) and pneumonia (1.7\%) [16]. Another study also reported similar results with maximum patients of PPROM (59.0\%) belonging to 21 25 years age group with mean age of $23.52 \pm 3.70$ years.

As opposed to the present study they found it more common in primigravida $(50 \%)$ as compared to multigravida. In their study also, vaginal delivery $(85.5 \%)$ was more common followed by cesarean section (14.5\%). They also concluded that PPROM was associated with adverse neonatal outcome with most common complication being Respiratory distress syndrome followed by neonatal sepsis [17]. Many other studies also reported a significant correlation between
PPROM and adverse perinatal outcome [18-21]. On contrary to this, a recent study reported that PPROM per se was not associated with adverse perinatal outcome, neither was it associated with increased risk of sepsis [5].

Limitations- The present study was conducted for a shorter duration and on a small sample of women with PPROM. Furthermore, the outcome was assessed for late PPROM only. In future an attempt will be made to conduct a study on larger sample including those with early PPROM ( $<28$ weeks).

\section{Conclusion}

Hence, PPROM significantly resulted in an increased risk of preterm deliveries and its associated complication, making it one of the most important causes for perinatal morbidities (including preterm births, low birth weight, poor Apgar scores at birth, increased NICU admission rates, need for intubation and neonatal complications) and mortality.

\section{What the study adds to existing knowledge?}

The present study depicts the impact of PPROM on overall perinatal outcome. It was observed that PPROM was associated with an overall perinatal mortality of $6.7 \%$ with Respiratory distress syndrome (44.0\%) and Jaundice $(8.0 \%)$ as most common neonatal morbidities. PPROM was significantly associated with poor Apgar scores at birth and increased NICU admission rates.

\section{Author's contribution}

Dr. Naina Kumar: Concept, Design, Literature search, Data analysis, Compilation and final check of manuscript.

Dr. Ashu Yadav: Literature search, Data analysis, Compilation and final check of manuscript.

Acknowledgement: Authors would like to thank Dr. Namit for his constant support.

Funding: Nil, Conflict of interest: Nil Permission from IRB: Yes

\section{References}

1. Yu H, Wang X, Gao H, You Y, Xing A. Perinatal outcomes of pregnancies complicated by preterm premature rupture of the membranes before 34 weeks of gestation in a tertiary center in China: A retrospective review. Biosci Trends. 2015;9(1):35-41. doi: 10.5582 / bst. 2014.01058 . 


\section{Original Research Article}

2. ACOG Committee on Practice Bulletins-Obstetrics. ACOG Practice Bulletin No. 80: premature rupture of membranes. Clinical management guidelines for obstetrician- gynecologists. Obstet Gynecol. 2007;109 (4) : 1007-1019. doi: 10.1097/01. AOG.0000263888. $69178.1 \mathrm{f}$

3. Caughey AB, Robinson JN, Norwitz ER. Contemporary diagnosis and management of preterm premature rupture of membranes. Rev Obstet Gynecol. 2008 Winter; 1(1):11-22.

4. Borna S, Borna H, Hantoushzadeh S. 'Perinatal outcome in preterm premature rupture of membranes with Amniotic fluid index $<5(\mathrm{AFI}<5)$. BMC Preg Childbirth. 2004;4(1):15.

5. Hanke K, Hartz A, Manz M, Bendiks M, Heitmann F, Orlikowsky $\mathrm{T}$ et al. Preterm prelabor rupture of membranes and outcome of very-low-birth-weight infants in the German Neonatal Network. PloS one. 2015; 10(4): e0122564. doi:10.1371/journal.pone. 0122 564.

6. Kumar D, Moore RM, Mercer BM, Mansour JM, Redline RW, Moore JJ. The physiology of fetal membrane weakening and rupture: Insights gained from the determination of physical properties revisited. Placenta. 2016; 42:59-73. doi: 10.1016/j.placenta. 2016. 03.015 .

7. Menon R, Richardson LS. Preterm prelabor rupture of the membranes: A disease of the fetal membranes. Semin Perinatol. 2017;41(7):409-419. doi: 10.1053/j. semperi.2017.07.012.

8. Mercer BM. Preterm premature rupture of the membranes: current approaches to evaluation and management. Obstet Gynecol Clinic. 2005;32(3):411428. doi:10.1016/j.ogc.2005.03.003.

9. Kenyon SL, Taylor DJ, Tarnow-Mordi W; ORACLE Collaborative Group. Broad-spectrum antibiotics for preterm, prelabour rupture of fetal membranes: the ORACLE I randomised trial. Oracle Collaborative Group. Lancet. 2001;357(9261):979-988. doi:10.1016 /s0140- 6736(00)04233-1

10. Huang S, Qi HB, Li L. [Residue amniotic fluid volume after preterm premature rupture of membranes and maternal-fetal outcome.]. Zhonghua Fu Chan Ke Za Zhi. 2009; 44(10):726-730. doi: 10.3760/cma.j.issn. 0529-567x. 2009.10.002
11. Tavassoli F, Ghasemi M, Mohamadzade A, Sharifian J. Survey of pregnancy outcome in preterm premature rupture of membranes with amniotic fluid index $<5$ and $\geq 5$. Oman Med J. 2010;25(2):118-123. doi: 10.5001/omj.2010.32.

12. Diraviyam JMV, Karunakaran L. Maternal and perinatal outcome in preterm premature rupture of membranes. Int J Reprod Contracept Obstet Gynecol. 2017; 6(6):2498-2502. doi: http://dx.doi.org/10.18203/ 2320-1770.ijrcog20172339.

13. Lovereen S, Khanum MA, Nargis N, Begum S, AfrozeR. Maternal and Neonatal outcome in premature rupture of membranes. Bangladesh Journal of Medical Science, 2018;17(3):479-483. https://doi.org/10. 3329/ bjms. v17i3.37004.

14. Sim WH, Ng H, Sheehan P. Maternal and neonatal outcomes following expectant management of preterm prelabor rupture of membranes before viability. J Matern Fetal Neonatal Med. 2018:1-9. doi: 10.1080/ 14767058.2018.1495706.

15. Sim WH, Araujo Júnior E, Da Silva Costa F, Sheehan PM. Maternal and neonatal outcomes following expectant management of preterm prelabour rupture of membranes before viability. J Perinat Med. 2017 Jan 1; 45 (1): 29-44. doi: 10.1515/ jpm- 20160183.

16. Lokhande S, Nistane R. Incidence of morbidity and mortality in neonate born to mothers with premature rupture of membranes. Int J Contemp Pediatr. 2016;3 (4): 1394-1400. doi:http://dx.doi.org/10.18203/23493291. ijcp 20163685.

17. Shukla P, Bhargava M. Study of maternal and fetal outcome in preterm premature rupture of membrane. $\mathrm{J}$ Evol Med Dent Sci. 2014;3(7):1789-1796. doi: 10. 14260/jemds/2014/2059.

18. Thayi S, Paramahamsa R. Outcome of newborns born to mothers with prolonged rupture of membrane. Int J Pediatr Res.2016;3(11):835-841.doi:10.17511/ijpr. 2016.11.13.

19. Shimokaze T, Akaba K, Banzai M, Kihara K, Saito E, Kanasugi H. Premature rupture of membranes and neonatal respiratory morbidity at 32-41 weeks' gestation: a retrospective single-center cohort study. J Obstet Gynaecol Res. 2015;41(8):1193-1200. doi: 10. 1111 / jog. 12689. Epub 2015 Apr 1. 


\section{Original Research Article}

20. Esteves JS, de Sá RA, de Carvalho PR, Coca Velarde LG. Neonatal outcome in women with preterm premature rupture of membranes (PPROM) between 18 and 26 weeks. J Matern Fetal Neonatal Med. 2016; 29 (7): 1108-1112. doi: 10.3109/14767058.2015.1035643. Epub 2015 Jul 3.
21. Nayot D, Penava D, Da Silva O, Richardson BS, de Vrijer B. Neonatal outcomes are associated with latency after preterm premature rupture of membranes. J Perinatol. 2012;32(12):970-977. doi: 10.1038/jp.2012. 15. Epub 2012 Mar

\section{How to cite this article?}

Kumar N Yadav A. Preterm pre-labor rupture of membranes and perinatal outcome: a prospective cohort study. Obs Rev: J obstet Gynecol 2019;5(3):169-175.doi:10.17511/joog.2019.i03.07. 